\title{
Knowledge and Attitudes of Sexually Transmitted Infections Among High School Students in Sarajevo
}

\author{
Sabina Mahmutovic Vranic ${ }^{1}$, Mufida Aljicevic ${ }^{1}$, Sabina Segalo ${ }^{1}$, Anes Joguncic ${ }^{2}$
}

${ }^{1}$ Department of Microbiology, School of Medicine University of Sarajevo, Sarajevo, Bosnia and Herzegovina, ${ }^{2}$ Department of Forensic Medicine, School of Medicine University of Sarajevo, Sarajevo, Bosnia and Herzegovina

\author{
Correspondence: \\ sabina.mahmutovic@mf.unsa.ba \\ Tel.: + 38733259781 \\ Fax.: + 38733203670
}

Received: 22 April 2019

Accepted: 8 August 2019

Key Words: Knowledge - Behaviour - Awareness - Sexually Transmitted Infections.

\section{Introduction}

Sexually transmitted infections (STIs) have been recognized as a major public and social health care problem worldwide (1). Their incidence is constantly increasing, and the young population bears a significant burden from these infections, as well as unwanted pregnancies and births, maternal deaths and abortion (2-4). According to data from the World Health Organization (WHO), more than 1 million STIs are reported every day worldwide (5). Each year, there are an estimated 357 million new infections from one

\begin{abstract}
Objective. The aim of the study was to evaluate knowledge and behavioural risks related to sexually transmitted infection (STIs) among high school students. Methods. The cross sectional study was conducted among students aged 15-18 years old from two high schools in the Sarajevo Canton in the period from October 2017 to March 2018. An anonymous self-administered questionnaire was used. The survey inlevel of knowledge about STIs. The data were analysed using SPSS version 25 and MS Excel 2016. Results. In total 278 high school students articipated in the study, with a mean age of $17.79 \pm 1.026$ years, of significant difference in age in relation to sex distribution $(\mathrm{P}=0.074)$. Regarding the number of participants, $234(84.2 \%)$ were from the denschool, while $44(15.8 \%)$ were from a gimnazija (grammar high tion by school $(\mathrm{P}=0.080)$. Students from the grammar high school had significantly better knowledge about the impact of STI on the foetus $\mathrm{P}=0.025)$ and infected individuals $(\mathrm{P}=0.001)$, also about the impact of ( Conclusion. Our study confirmed the need or implementation of sexual education programs in the final grades of elementary school or in first grades of high school, aimed at imsexual and reproductive health.
\end{abstract}

(1) of four (4) curable STIs: chlamydia, gonorrhoea, syphilis and trichomoniasis. The majority of STIs have no or only mild symptoms that may not be recognized as STIs (5).

Generally, sexual and reproductive health care among young people has faced major problems, challenges and dilemmas. Therefore, it is necessary to understand the level of awareness and knowledge about STIs, methods of protection, and sexual practices in this group of individuals. It is important to emphasize youth as the most vulnerable group, with an increase in the birth rate, 
especially in adolescents aged less than 15 years old, who primarily live in undeveloped countries with poor social and health care support programs (4). Approximately $70 \%$ of patients with STIs are in the age range between 15 and 24 years old. The WHO estimates that one in twenty teenagers contracts an STI during their lifetime (5).

In the context of Bosnia and Herzegovina $(\mathrm{BH})$, the most important factors that contribute to the spread of STIs are the lack of sexual education in the school system, inconsistent and irregular condom use, casual sexual partners, and an inadequate level of knowledge about STI prevention strategies (6), which are predominant in this population. However, a low coverage of vaccine against human papillomavirus (HPV) infection has also been observed in $\mathrm{BH}$ due to the insufficient adherence of parents and adolescents to the health care system, for a variety of reasons (belief in the adverse effect of vaccines without scientific medical knowledge, the lack of interest of social and health care workers for recognition of HPV as being an STI, cultural and social aspects).

In this paper, some limitations in relation to the factors that may result in risk-taking behaviours are presented, mainly personal, family or social/school-related (6). Relatively little is known about the socio-demographic factors and sexual behaviour, having in mind the specificity of this population. Although a few studies have been carried out on this topic in $\mathrm{BH}$, the fact is that research of this type needs to be seriously understood and resumed on a high-quality sample in this category, and compared with the available literature $(6,7)$. In most other countries in Eastern Europe, as in $\mathrm{BH}$, there is lack of data about the prevalence of the most curable STIs in the general population, including youth (8).

Therefore this study was conducted to assess awareness about STIs in a young population, and determine the relationship between socio-demographic factors and knowledge of STIs among high school students in Sarajevo Canton, BH. Furthermore, our goal was to determine correlations between the students' socio-demographic characteristics, sexual behaviour and knowledge about STIs, and compare the results with other relevant studies on the topic.

\section{Material and Methods}

\section{Study Population}

This was a cross-sectional study design, conducted in Sarajevo Canton, BH. In total, 278 high school students, attending the third and fourth grades at two high schools were included in the study, during the period of October 2017 to March 2018. The multistage sampling method, followed by a simple random sampling technique was used to collect the primary data, with a sample size of $84.2 \%$ students from the dental school, and $15.8 \%$ from the grammar high school. A semi-structured, self-administered written questionnaire (SAQ) was used for collecting data about knowledge, attitudes and practice in the high school population.

\section{The Questionnaire}

For the purpose of this research, a special questionnaire was developed, based on several existing foreign instruments. As a base, the following instruments were used and modified (9-12): the Sexual Activities \& Attitudes Questionnaire (Noll at all, 2003), the Teenage Sexual Health and Behaviour Questionnaire (Jomeen and Whithfield, 2010), Survey of Sexual Behaviours (Coulter, 2007) and the Youth Risk Behaviour Survey (Centres for Disease Control and Prevention, 2011). The survey questionnaire consisted of two fundamental parts, including 33 questions about sexual experience, attitudes and beliefs related to sexual relations, use 
of condoms as protection, their perception of sexual activity, and a test of reproductive and sexual health.

The first part comprised 15 items: demographic and socio-economic questions (gender, age, the high school that the student attends, grade, municipality of residence, socio-economic status, who they live with, the type of family they live in). The type of family: liberal or conservative was examined to see how students see their personal home environment, because liberal families tend to be more open for conversation about these delicate topics. In some cases students found their parents liberal, for example in relation to cigarettes or going out, but conservative on topics such as sexuality. The next set of questions was about their social life: how often they go out, whether they have a curfew by which they must be at home, also alcohol consumption and smoking cigarettes or using a water pipe to filter smoke, known also as a hookah. The last question was only for girls, regarding their first menstrual period. The second part contained 18 items that we used for testing their knowledge, awareness, attitudes, sexual behaviour and experience, history of STIs, and condom use. The questions were as follows: first sexual intercourse, use of contraceptive methods, number of partners, sexual preferences, and condom usage during the last sexual relationship. Additionally, there were questions about their knowledge of sexually transmitted infections, their causes, the most effective forms of protection, and the consequences. The questionnaire could be answered within 10-15 minutes. The survey procedure was designed to protect the student's privacy, with anonymous participation and participation was not mandatory. The processing and publication of participants' data in this study were strictly in accordance with the Declaration of Helsinki, DoH/Oct2008, including confidentiality and anonymity. Medical doctors, who work at the Department of Microbiology at Medical Faculty, University of Sarajevo presented and explained the meaning of the questionnaire to the students.

\section{Indicators}

Socio-economic status was measured by 3 -point scales ranging from (1) worse than others in the area to (3) better than others in the area. An indicator of parental control was obtained by categorizing respondents on the basis of where they live and with whom. Respondents living with both parents were coded by a 5 -point scale ranging from (1) in a student hostel to (5) with parents. Frequency of condom use was accessed by a 2-point scale ranging from (1) never to (2) always. Responses regarding the number of sexual partners were collapsed into categories: 1-3 partners, 4 or more partners and a "No answer" group.

Answers about the age of the last sexual partner were split into two categories: older than subject or of the same age. Use of condoms during last sexual intercourse was tested with a yes or no question type. Oral sexual intercourse was also tested in the same way. The questions about knowledge of STIs also had only yes and no answers. Knowledge about STIs was tested by a question where the subjects had to mark all the STIs that they know about. These diseases were: Chlamydia, Tuberculosis (TBC), Syphilis, Flu, HIV, Gonorrhoea, and Measles.

We asked about where the subjects obtained their first information about sexual intercourse and possible infections on the basis of eight answers. Also knowledge about the best protection from STIs was tested with the possible answers: oral contraceptives, coil, condom, lubricant. Consequences of STI infection were tested with a question about whom they affect, only the infected persons, or even a pregnancy. 


\section{Statistical Analysis}

Basic standard methods of descriptive statistics, quantitatively describing or summarizing features of a collection of information were used. Values were represented in frequencies or as a percentage. Chi-square test or Fisher exact test was performed to test the differences in proportions of qualitative variables between groups and Student t-test for testing the differences between quantitative variables. The data were analysed with IBM SPSS Statistics 25.00 (IBM Corporation, Armonk, New York) and MS-Excel. Statistical significance was established with $\mathrm{p}$ values less than 0.05 .

\section{Results}

A total of 278 high school students participated in the study, with a mean age of $17.79 \pm 1.03$ years. Eighty-nine (32\%) were male, while 189 (68\%) were female. There was no significant difference in sex distribution in relation to age $(\mathrm{P}=0.074)$. Regarding the number of participants, $234(84.2 \%)$ were from the dental school, while 44 (15.8\%) were from the grammar high school. There was no significant difference in genderbased distribution by school $(\mathrm{P}=0.08)$. The number of questionnaires that were completely answered was 197 of the 278 that were answered (response rate $70.9 \%$ ). The questions that were not answered by all students were analysed.

The demographic characteristics of the participants were analysed as follows: the municipalities where they lived, socioeconomic status, living situation and family type, frequency of evening outings and curfew limitations. These are shown in Table 1.

No significant demographic differences were found in the characteristics of the respondents based on the school they were attending. The type of family that students came from was similar in both schools. Most of them believed that their family was liberal, but in some situations it was conservative.

The risk factors faced by students from both schools are similar in distribution. The values are shown in Table 2.

Alcohol was regularly consumed by $17.2 \%$ of students at the dental school, occasionally by $24.3 \%$ of respondents; while $27.3 \%$ of the grammar high school students regularly consumed alcohol, with occasional alcohol consumption by $18.2 \%$ of respondents. Cigarettes were smoked by $18.0 \%$ of the respondents in the dental school, while $22.7 \%$ grammar high school students smoked. Some form of drug had been consumed by $2.6 \%$ of respondents in the dental school and $4.6 \%$ of the respondents in the grammar high school. Hookahs were used by about one-third of the population in both schools. No significant differences in exposure to risk factors were found.

The replies related to menstrual cycle, sexual relations, protection and contraception, the number of partners are shown in Table 3.

The first menstruation, in over $50 \%$ of females, was between the ages of 12 and 14 in both schools. The first menstrual period was at under the age of 12 in $24.7 \%$ of respondents in the dental school, , and in $34.3 \%$ in the grammar high school. There was no significant difference in distribution. $20.9 \%$ of the III and IV grade students of the dental school had had sexual relations, and $18.2 \%$ of the respondents in the grammar high school. In the dental school $83.3 \%$ of the respondents, and $57.1 \%$ of the respondents in the grammar high school used some form of protection. There was no significant difference (Fishers exact test $\mathrm{P}=0.139$ ).

According to the results, the condom is the form of contraception used most often by all high school students. In total, $91.1 \%$ respondents used condoms in the dental school, and $71.4 \%$ of the respondents in the grammar high school. In the dental school, 
Table 1. Demographic Characteristics of High School Students

\begin{tabular}{|c|c|c|c|c|c|c|c|}
\hline \multirow{3}{*}{ Variable } & \multirow{3}{*}{ Characteristics } & \multicolumn{4}{|c|}{ Schools } & \multirow{2}{*}{\multicolumn{2}{|c|}{ Total }} \\
\hline & & \multicolumn{2}{|c|}{ Dental School } & \multicolumn{2}{|c|}{ Gymnasium } & & \\
\hline & & $\mathrm{N}$ & $\%$ & $\mathrm{~N}$ & $\%$ & $\mathrm{~N}$ & $\%$ \\
\hline \multirow{3}{*}{ Gender } & Female & 154 & 65.8 & 35 & 79.5 & 189 & 67.9 \\
\hline & Male & 80 & 34.2 & 9 & 20.5 & 89 & 32.0 \\
\hline & Total & 234 & 100.0 & 44 & 100.0 & 278 & 100.0 \\
\hline \multirow{2}{*}{ Age (yr) } & Female & \multicolumn{2}{|l|}{$18 \pm 1$} & \multicolumn{2}{|c|}{$17 \pm 2$} & \multicolumn{2}{|c|}{$18 \pm 1$} \\
\hline & Male & \multicolumn{2}{|l|}{$18 \pm 1$} & \multicolumn{2}{|c|}{$18 \pm 1$} & \multicolumn{2}{|c|}{$18 \pm 1$} \\
\hline \multirow{11}{*}{ Municipalities } & Stari Grad & 25 & 11.2 & 10 & 23.3 & 35 & 13.2 \\
\hline & Centar & 33 & 14.8 & 12 & 27.9 & 45 & 16.9 \\
\hline & Novo Sarajevo & 32 & 14.4 & 3 & 6.9 & 35 & 13.2 \\
\hline & Novi Grad & 53 & 23.8 & 11 & 25.6 & 64 & 24.1 \\
\hline & Ilidža & 32 & 14.4 & 5 & 11.6 & 37 & 13.9 \\
\hline & Hadžići & 6 & 2.7 & 0 & 0.0 & 6 & 2.3 \\
\hline & Vogošća & 30 & 13.5 & 2 & 4.7 & 32 & 12.0 \\
\hline & Ilijaš & 10 & 4.5 & 0 & 0.0 & 10 & 3.7 \\
\hline & Zenica & 1 & 0.5 & 0 & 0.0 & 1 & 0.4 \\
\hline & Visoko & 1 & 0.5 & 0 & 0.0 & 1 & 0.4 \\
\hline & Total & 223 & 100.0 & 43 & 100.0 & 266 & 100.0 \\
\hline \multirow{4}{*}{ Socio-economic status } & Worse & 3 & 1.3 & 1 & 2.3 & 4 & 1.5 \\
\hline & Average & 197 & 85.3 & 34 & 77.3 & 231 & 84.0 \\
\hline & Better & 31 & 13.4 & 9 & 20.5 & 40 & 14.6 \\
\hline & Total & 231 & 100.0 & 44 & 100.0 & 275 & 100.0 \\
\hline \multirow{5}{*}{ Living with } & Parents & 216 & 92.7 & 41 & 93.2 & 257 & 92.8 \\
\hline & Guardians & 7 & 3.0 & 1 & 2.3 & 8 & 2.9 \\
\hline & Alone & 7 & 3.0 & 2 & 4.6 & 9 & 3.3 \\
\hline & Roommate & 3 & 1.3 & 0 & 0.0 & 3 & 1.1 \\
\hline & Total & 233 & 100.0 & 44 & 100.0 & 277 & 100.0 \\
\hline \multirow{4}{*}{ Family type } & Conservative & 29 & 13.2 & 6 & 14.3 & 35 & 13.4 \\
\hline & Liberal & 93 & 42.3 & 18 & 42.9 & 111 & 42.4 \\
\hline & Both types & 98 & 44.5 & 18 & 42.9 & 116 & 44.3 \\
\hline & Total & 220 & 100.0 & 42 & 100.0 & 262 & 100.0 \\
\hline \multirow{4}{*}{ Evening outings } & Till $3 x$ & 72 & 31.2 & 16 & 37.2 & 88 & 32.1 \\
\hline & On weekends & 80 & 34.6 & 10 & 23.3 & 90 & 32.9 \\
\hline & On a daily basis & 79 & 34.2 & 17 & 39.5 & 96 & 35.0 \\
\hline & Total & 231 & 100.0 & 43 & 100.0 & 274 & 100.0 \\
\hline \multirow{3}{*}{ Length limitations } & Yes & 140 & 60.3 & 28 & 65.1 & 168 & 61.1 \\
\hline & No & 92 & 39.7 & 15 & 34.9 & 107 & 38.9 \\
\hline & Total & 232 & 100.0 & 43 & 100.0 & 275 & 100.0 \\
\hline
\end{tabular}


Acta Medica Academica 2019;48(2):147-158

Table 2. Consumption of Risk Factors

\begin{tabular}{|c|c|c|c|c|c|c|c|}
\hline \multirow{3}{*}{ Consumption } & \multirow{3}{*}{ Indicators } & \multicolumn{4}{|c|}{ Schools } & \multirow{2}{*}{\multicolumn{2}{|c|}{ Total }} \\
\hline & & \multicolumn{2}{|c|}{ Dental school } & \multicolumn{2}{|c|}{ Gymnasium } & & \\
\hline & & $\mathrm{N}$ & $\%$ & $\mathrm{~N}$ & $\%$ & $\mathrm{~N}$ & $\%$ \\
\hline \multirow{4}{*}{ Alcohol } & Yes & 40 & 17.2 & 12 & 27.3 & 52 & 18.8 \\
\hline & No & 136 & 58.4 & 24 & 54.6 & 160 & 57.8 \\
\hline & Periodically & 57 & 24.5 & 8 & 18.2 & 65 & 23.5 \\
\hline & Total & 233 & 100.0 & 44 & 100.0 & 277 & 100.0 \\
\hline \multirow{4}{*}{ Cigarettes } & Yes & 42 & 18.0 & 10 & 22.7 & 52 & 18.8 \\
\hline & No & 165 & 70.8 & 32 & 72.7 & 197 & 71.1 \\
\hline & Periodically & 26 & 11.2 & 2 & 4.6 & 28 & 10.1 \\
\hline & Total & 233 & 100.0 & 44 & 100.0 & 277 & 100.0 \\
\hline \multirow{4}{*}{ Narcotics } & Yes & 6 & 2.6 & 2 & 4.7 & 8 & 2.9 \\
\hline & No & 213 & 91.4 & 36 & 83.7 & 249 & 90.2 \\
\hline & Tried & 14 & 6.01 & 5 & 11.6 & 19 & 6.9 \\
\hline & Total & 233 & 100.0 & 43 & 100.0 & 276 & 100.0 \\
\hline \multirow{4}{*}{ Hookah } & Yes & 73 & 31.5 & 17 & 39.5 & 90 & 32.7 \\
\hline & No & 110 & 47.4 & 18 & 41.9 & 128 & 46.6 \\
\hline & Periodically & 49 & 21.1 & 8 & 18.6 & 57 & 20.7 \\
\hline & Total & 232 & 100.0 & 43 & 100.0 & 275 & 100.0 \\
\hline
\end{tabular}

Table 3. Sexual Behaviour Knowledge Protection and Contraception

\begin{tabular}{|c|c|c|c|c|c|c|c|}
\hline \multirow{3}{*}{ Variable } & \multirow{3}{*}{ Indicators } & \multicolumn{4}{|c|}{ Schools } & \multirow{2}{*}{\multicolumn{2}{|c|}{ Total }} \\
\hline & & \multicolumn{2}{|c|}{ Dental school } & \multicolumn{2}{|c|}{ Gymnasium } & & \\
\hline & & $\mathrm{N}$ & $\%$ & $\mathrm{~N}$ & $\%$ & $\mathrm{~N}$ & $\%$ \\
\hline \multirow{4}{*}{ Menstrual cycles } & $<12 \mathrm{yr}$. & 38 & 24.7 & 12 & 34.3 & 50 & 26.5 \\
\hline & 12 do $14 \mathrm{yr}$. & 90 & 58.4 & 19 & 54.3 & 109 & 57.7 \\
\hline & $>14$ years & 26 & 16.9 & 4 & 11.4 & 30 & 15.9 \\
\hline & Total & 154 & 100.0 & 35 & 100.0 & 189 & 100.0 \\
\hline \multirow{3}{*}{ Sexual relations } & Yes & 49 & 20.9 & 8 & 18.2 & 57 & 20.5 \\
\hline & No & 185 & 79.1 & 36 & 81.8 & 221 & 79.5 \\
\hline & Total & 234 & 100.0 & 44 & 100.0 & 278 & 100.0 \\
\hline \multirow{3}{*}{ Protection } & Yes & 35 & 83.3 & 4 & 57.1 & 39 & 79.6 \\
\hline & No & 7 & 16.7 & 3 & 42.9 & 10 & 20.4 \\
\hline & Total & 42 & 100.0 & 7 & 100.0 & 49 & 100.0 \\
\hline \multirow{3}{*}{ Contraception } & No & 4 & 8.9 & 2 & 28.6 & 6 & 12.2 \\
\hline & Condom & 41 & 91.1 & 5 & 71.4 & 46 & 93.9 \\
\hline & Total & 42 & 100.0 & 7 & 100.0 & 49 & 100.0 \\
\hline \multirow{3}{*}{ Number of partners } & 1 to 2 partners & 30 & 63.8 & 6 & 85.7 & 36 & 66.7 \\
\hline & $\geq 3$ partners & 17 & 36.2 & 1 & 14.3 & 18 & 33.3 \\
\hline & Total & 47 & 100.0 & 7 & 100.0 & 54 & 100.0 \\
\hline \multirow{3}{*}{ Partners age } & Same years & 22 & 46.8 & 4 & 57.1 & 26 & 48.2 \\
\hline & Older & 25 & 53.3 & 3 & 42.9 & 28 & 51.8 \\
\hline & Total & 47 & 100.0 & 7 & 100.0 & 54 & 100.0 \\
\hline \multirow{3}{*}{$\begin{array}{l}\text { Condom use during the last } \\
\text { sexual intercourse }\end{array}$} & Yes & 30 & 65.2 & 4 & 57.1 & 34 & 64.1 \\
\hline & No & 16 & 34.8 & 3 & 42.9 & 19 & 35.8 \\
\hline & Total & 46 & 100.0 & 7 & 100.0 & 53 & 100.0 \\
\hline \multirow{3}{*}{ Oral sex } & Yes & 45 & 25.8 & 8 & 20.5 & 53 & 24.9 \\
\hline & No & 129 & 74.1 & 31 & 79.5 & 160 & 75.1 \\
\hline & Total & 174 & 100.0 & 39 & 100.0 & 213 & 100.0 \\
\hline
\end{tabular}


$8.9 \%$ did not use contraception and in the grammar high school $28.6 \%$.

Most of the respondents in both schools had had 1 or 2 sexual partners. In the dental school, $53.2 \%$ of those who had had sexual experience stated that the partner was older, while $57.1 \%$ of the grammar high school students had had partners of the same age.
Knowledge about STIs was tested by a questionnaire and the results are presented in Table 4.

Analysing the STI survey results, significant differences in students' knowledge were identified. In the survey questionnaire, only $45.8 \%$ of dental school students recognized chlamydia as a causative agent of

Table 4. Knowledge about STIs

\begin{tabular}{|c|c|c|c|c|c|c|c|}
\hline \multirow{3}{*}{ Variable } & \multirow{3}{*}{ Indicators } & \multicolumn{4}{|l|}{ Schools } & \multirow{2}{*}{\multicolumn{2}{|c|}{ Total }} \\
\hline & & \multicolumn{2}{|c|}{ Dental school } & \multicolumn{2}{|c|}{ Gymnasium } & & \\
\hline & & $\mathrm{N}$ & $\%$ & $\mathrm{~N}$ & $\%$ & $\mathrm{~N}$ & $\%$ \\
\hline \multirow{6}{*}{$\begin{array}{l}\text { Knowledge } \\
\text { about STIs }\end{array}$} & Poorly & 5 & 2.3 & 1 & 2.3 & 6 & 2.3 \\
\hline & Poor & 18 & 8.1 & 1 & 2.3 & 19 & 7.2 \\
\hline & Neither good nor bad & 67 & 30.3 & 19 & 43.2 & 86 & 32.4 \\
\hline & Good & 96 & 43.4 & 16 & 36.4 & 112 & 42.3 \\
\hline & Very good & 35 & 15.8 & 7 & 15.9 & 42 & 15.8 \\
\hline & Total & 221 & 100.0 & 44 & 100.0 & 265 & 100.0 \\
\hline \multirow{3}{*}{$\begin{array}{l}\text { Chlamydia } \\
\text { marked }\end{array}$} & Yes & 93 & 45.8 & 36 & $87.8^{*}$ & 129 & 52.9 \\
\hline & No & 110 & 54.2 & 5 & 12.2 & 115 & 47.1 \\
\hline & Total & 203 & 100.0 & 41 & 100.0 & 244 & 100.0 \\
\hline \multirow{3}{*}{$\begin{array}{l}\text { TBC } \\
\text { marked }\end{array}$} & Yes & 10 & 4.9 & 1 & 2.4 & 11 & 4.5 \\
\hline & No & 194 & 95.1 & 40 & 97.6 & 234 & 95.5 \\
\hline & Total & 204 & 100.0 & 41 & 100.0 & 245 & 100.0 \\
\hline \multirow{3}{*}{$\begin{array}{l}\text { Syfilis } \\
\text { marked }\end{array}$} & Yes & 168 & 82.4 & 35 & 85.4 & 203 & 82.9 \\
\hline & No & 36 & 17.7 & 6 & 14.6 & 42 & 17.1 \\
\hline & Total & 204 & 100.0 & 41 & 100.0 & 245 & 100.0 \\
\hline \multirow{3}{*}{$\begin{array}{l}\text { Flu } \\
\text { marked }\end{array}$} & Yes & 5 & 2.4 & 1 & 2.4 & 6 & 2.4 \\
\hline & No & 199 & 97.5 & 41 & 97.6 & 240 & 97.6 \\
\hline & Total & 204 & 100.0 & 42 & 100.0 & 246 & 100.0 \\
\hline \multirow{3}{*}{$\begin{array}{l}\text { HIV } \\
\text { marked }\end{array}$} & Yes & 194 & 95.1 & 40 & 97.6 & 234 & 95.5 \\
\hline & No & 10 & 4.9 & 1 & 2.4 & 11 & 4.5 \\
\hline & Total & 204 & 100.0 & 41 & 100.0 & 245 & 100.0 \\
\hline \multirow{3}{*}{$\begin{array}{l}\text { Measles } \\
\text { marked }\end{array}$} & Yes & 7 & 3.4 & 1 & 2.4 & 8 & 3.3 \\
\hline & No & 197 & 96.6 & 40 & 97.6 & 237 & 96.7 \\
\hline & Total & 204 & 100.0 & 41 & 100.0 & 245 & 100.0 \\
\hline \multirow{3}{*}{ Gonorrhea } & Yes & 134 & 65.7 & 25 & 60.9 & 159 & 64.9 \\
\hline & No & 70 & 34.3 & 16 & 39.1 & 86 & 35.1 \\
\hline & Total & 204.00 & 100.0 & 41 & 100.0 & 245 & 100.0 \\
\hline \multirow{6}{*}{$\begin{array}{l}\text { Number of } \\
\text { correct answers }\end{array}$} & $0-1$ correct answer & 21 & 10.2 & 2 & 4.9 & 23 & 9.4 \\
\hline & 2 correct answers & 45 & 21.9 & 5 & 12.2 & 50 & 20.3 \\
\hline & 3 correct answers & 69 & 33.7 & 12 & 29.3 & 81 & 32.9 \\
\hline & 4 correct answers & 70 & 34.2 & 22 & 53.7 & 92 & 37.5 \\
\hline & 5 - 7 correct answers & 0 & 0 & 0 & 0 & 0 & 0 \\
\hline & Total & 205 & 100.0 & 41 & 100.0 & 246 & 100.0 \\
\hline
\end{tabular}

STIs=Sexually transmitted infections. 
STIs, in contrast to $87.8 \%$ of respondents in the grammar high school. There was a significant difference (Chi-square test $=24.14$, $\mathrm{P}<0.001)$. Knowledge about other possible pathogens was similar, without any significant difference. In total, none of subjects gave more than 4 correct answers.

That a condom is effective protection is believed by $84.8 \%$ of respondents in the dental school and $79.5 \%$ of the respondents in the grammar high school (Table 5.). Oral contraceptives are seen as effective protec- tion during intercourse by $7.6 \%$ of respondents in the dental school and $2.3 \%$ of respondents from the grammar high school. From the grammar high school $6.8 \%$ of the respondents believed that a coil is an effective method. Students from the grammar high school had significantly better knowledge about the impact of STIs on the foetus (Fisher exact test $\mathrm{P}=0.025$ ) and infected individuals (Fisher Exact test $\mathrm{P}=0.001$ ). Also students from the grammar high school had significantly better knowledge about the

Table 5. Attitude and Practice

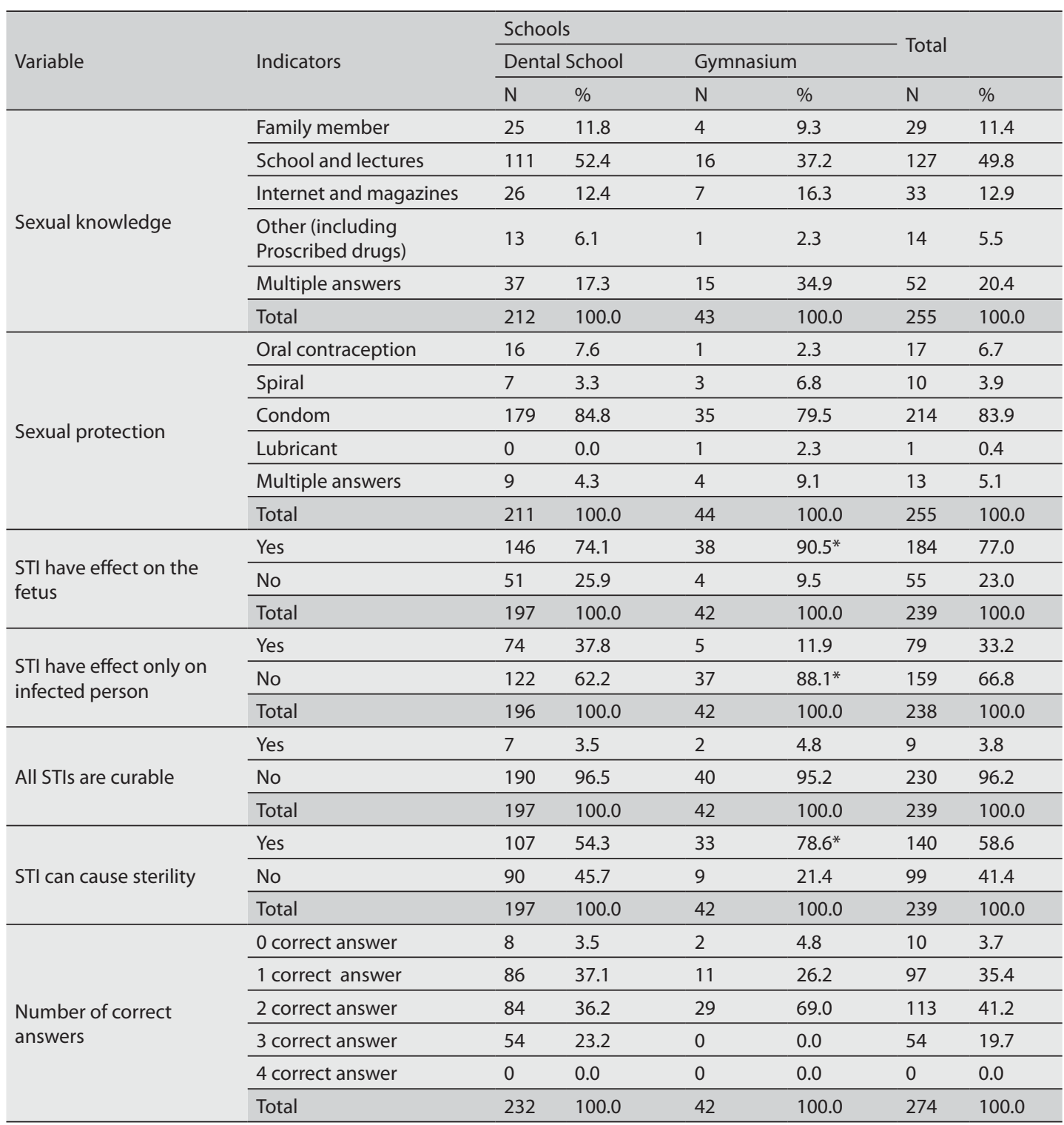


Continuation of Table 5. Attitude and Practice

\begin{tabular}{|c|c|c|c|c|c|c|c|}
\hline \multirow{3}{*}{ Variable } & \multirow{3}{*}{ Indicators } & \multicolumn{4}{|c|}{ Schools } & \multirow{2}{*}{\multicolumn{2}{|c|}{ Total }} \\
\hline & & \multicolumn{2}{|c|}{ Dental School } & \multicolumn{2}{|c|}{ Gymnasium } & & \\
\hline & & $\mathrm{N}$ & $\%$ & $\mathrm{~N}$ & $\%$ & $\mathrm{~N}$ & $\%$ \\
\hline \multirow{9}{*}{$\begin{array}{l}\text { Do you have any of } \\
\text { following symptoms }\end{array}$} & Urethral discharge & 0 & 0.0 & 0 & 0.0 & 0 & 0.0 \\
\hline & Vaginal discharge & 5 & 2.9 & 0 & 0.0 & 5 & 2.4 \\
\hline & Problem with urination & 0 & 0.0 & 1 & 2.4 & 1 & 0.5 \\
\hline & Itching & 5 & 2.7 & 1 & 2.4 & 6 & 2.9 \\
\hline & Bleeding & 3 & 1.8 & 0 & 0.0 & 3 & 1.4 \\
\hline & Abdominal pain & 1 & 0.6 & 1 & 2.4 & 2 & 0.9 \\
\hline & Nothing mentioned above & 153 & 90.5 & 37 & 90.2 & 190 & 90.5 \\
\hline & Other & 2 & 1.2 & 1 & 2.4 & 3 & 1.4 \\
\hline & Total & 169 & 100.0 & 41 & 100.0 & 210 & 100.0 \\
\hline \multirow{4}{*}{$\begin{array}{l}\text { Transmission of HIV by } \\
\text { kiss }\end{array}$} & Yes & 18 & 8.7 & 5 & 11.4 & 23 & 9.2 \\
\hline & No & 138 & 66.7 & 34 & 77.3 & 172 & 68.5 \\
\hline & Do not know & 51 & 24.6 & 5 & 11.4 & 56 & 22.3 \\
\hline & Total & 207 & 100.0 & 44 & 100.0 & 251 & 100.0 \\
\hline \multirow{6}{*}{ Unwanted pregnancy } & Conversation with parents & 108 & 52.2 & 21 & 48.8 & 129 & 51.6 \\
\hline & Abortion & 38 & 18.4 & 9 & 20.9 & 47 & 18.8 \\
\hline & Parenthood & 39 & 18.8 & 3 & 7.0 & 42 & 16.8 \\
\hline & Other & 10 & 4.8 & 7 & 16.3 & 17 & 6.8 \\
\hline & Multiple answers & 12 & 5.8 & 3 & 6.9 & 15 & 6.0 \\
\hline & Total & 207 & 100.0 & 43 & 100.0 & 250 & 100.0 \\
\hline \multirow{3}{*}{ Long lasting relationship } & Yes & 75 & 34.2 & 13 & 30.2 & 88 & 33.6 \\
\hline & No & 144 & 65.8 & 30 & 69.8 & 174 & 66.4 \\
\hline & Total & 219 & 100.0 & 43 & 100.0 & 262 & 100.0 \\
\hline
\end{tabular}

STIs=Sexually transmitted infections.

possible impact of STI on sterility (Fisher Exact test $\mathrm{P}=0.005)$. In total $23.3 \%$ of students in the dental school and $0 \%$ in the grammar high school had 3 correct answers about attitudes and practice. Furthermore, $36.2 \%$ of students in the dental school and $69.1 \%$ in the grammar high school had 2 correct answers. It is interesting that none of the students in either school had 4 correct answers. Answers to questions about unwanted pregnancy showed that around half of the students from both schools would talk with their parents, furthermore $18.8 \%$ of students from the dental school would choose parenthood no matter what, while only $7.0 \%$ of students in the grammar high school would choose parenthood no matter what. Abortion is an option for $18.8 \%$ of students in the dental school and for $20.9 \%$ in the grammar high school.

\section{Discussion}

Analysis of the results revealed significant demographic differences in the characteristics of high school students, based on the school they were attending. The type of family that students come from is similar in both high schools. Most believe that their family is liberal about topics such as sexuality and sexual education, but some students see their families as conservative. Moreover, no significant differences in risk factors were found. Risk factors in the study conducted by Drago et al., showed that in Italy $79 \%$ of responders used alcohol, especially at parties (58\%) and during weekends (22\%) (13). Alcohol usage and the presence of risk factors is much higher between Italian students than in $\mathrm{BH}$.

Similar results to ours were obtained by Thapa et al. in their study of high school 
students in Bajhang, Nepal, where awareness about STIs was $62.3 \%$, but only $38.1 \%$ had good knowledge, while $61.9 \%$ had poor knowledge about STIs (15) Another study conducted in Bangladesh showed that 70.6\% adolescents had awareness about STIs (16). About $19.1 \%$ of high school students tested in South Western Nigeria showed poor knowledge, while $74.1 \%$ had fair knowledge and $6.9 \%$ had good knowledge of sexually transmitted infections (17).

The possible cause of the variations in awareness and knowledge about STIs found in the data collected from the students from the two different high schools in our study is perhaps the difference in the subjects taught at the schools. Across Germany, nearly all students had heard of HIV, but overall knowledge of other STIs was much less satisfactory, with low self-reported knowledge and high levels of ignorance regarding individual STIs (14). Moreover, in our study, recognition of chlamydia as an STI agent was more familiar to students from the grammar high school than the dental school ( $87.8 \%$ vs. $45.8 \%)$, which is interesting because the dental students were attending medically oriented courses $(\mathrm{P}<0.001)$. Results obtained by von Rosen et al. in Germany, showed that more than $46 \%$ of participants had never heard of chlamydia and merely $18 \%$ knew that chlamydia can be cured. Knowledge and awareness were visibly lower for other STIs, of which the most frequently known infection was hepatitis B. Despite being the bacterial STI with the highest prevalence, chlamydia was the infection with the lowest proportion of participants claiming good knowledge and the lowest rate of awareness (14).

Regarding sexual intercourse, $20.94 \%$ of students in the dental school had had sexual intercourse, and $18.18 \%$ in the grammar high school. These results are much lower than in an Italian study, where $61 \%$ of respondents had already had sexual intercourse with the average age of the first sexual intercourse of $15.5 \pm 1.5$ years $(13)$.

Regarding preventive measures, $84.83 \%$ of the dental school students considered that condoms are effective protection, as well as $79.5 \%$ of the grammar high school students. The effectiveness of condoms in preventing STIs is well defined, but consistent condom usage has remained a challenge. Hirsl-Hecej et al. showed that the acceptance of condom use had slightly but significantly increased in comparison to the wave of 1997, and respondents in a 2001 survey among metropolitan high school students in Croatia were more likely to mention the importance of condom use $(18,20)$. The increase in condom use could be attributed to the increasingly open and informative media addressing adolescent sexuality. According to our results, $91.1 \%$ dental students used condom protection against STIs during their latest sexual intercourse, as well as $71.4 \%$ from the grammar high school. The decline in condom use among sexually active students is consistent with the findings of other studies, indicating that it decreases with consolidation of adolescent relationships $(13,18,19)$. Drago et al. in their study in Italy showed that students were using contraceptive methods much less than in BH: $37.3 \%$ used condoms, $6.5 \%$ used contraceptive pills, $2.1 \%$ both condom and contraceptive pills, while $41 \%$ were not currently using contraceptive methods (13). We also examined the dynamics of multiple sexual partners, and students reported mostly 1 or 2 partners (61.2\% vs. $85.7 \%)$, but this did not reach statistical significance, which is certainly good because there is a smaller chance of contracting STIs with regular partners. Also having a greater number of sex partners was associated with diagnosis of an STI. In addition, a greater number of concurrent partners had a significant correlation with STIs (21). A few students reported having 3 or more sexual partners, which can be explained by the de- 
sire to gain a certain reputation among their colleagues. Unfortunately, the limitations of the questionnaire used in the study preclude us from testing this hypothesis.

The next items in our study showed than in a case of unwanted pregnancy around half of the students from both schools would talk with their parents, furthermore $18.8 \%$ of students from the dental school would choose parenthood no matter what, while only $7.0 \%$ of students in the grammar high school would choose parenthood no matter what. Abortion is an option for $18.8 \%$ of students in the dental school and for 20.9\% in the grammar high school. Regarding the knowledge and transmission of HIV by kissing there was no significant difference. According to the data from the Croatian Institute of Public Health (20) in 2013 almost 1,300 girls gave birth between 15 and 19 years of age $(3.2 \%$ of the total number of births, 10.6 births per 1000 adolescents at the age of 15-19) and about 220 pregnancy terminations were recorded at the request of women up to 19 years of age. These results show how important it is to emphasize the prevention of juvenile pregnancies.

Students from the grammar high school in our study showed significantly better knowledge and attitudes about STIs, which is interesting since they are not undergoing medical education. No similar results from other studies were found for comparison. Hirsl-Hecej et al. reported higher levels of knowledge about HIV, which is important considering that during the observed period there was no systematic sex education in their schools (18).

\section{Limitations of the Study}

There are several limitations to this study. This paper observed students from two different high schools in Sarajevo Canton, therefore the results may not be generalizable to other high school populations. As has been seen in other studies $(14,15)$ young people who are sexually active and those who have had STIs appear to be more knowledgeable than those who are not. This lack of information may disguise other important correlates of young people's STI knowledge.

\section{Conclusion}

While the majority of high school students are aware about sexually transmitted infections, their knowledge is inadequate. Schoolbased programs remain the main way by which students learn about STIs. Our study confirmed the necessity for implementation of sexual education programs, perhaps in the final grades of elementary school or in the early ones of high school, aimed at improving knowledge of sexually transmitted infections, and increasing sexual and reproductive health.

\begin{abstract}
What Is Already Known on this Topic
Sexually transmitted infections have an important place as a continuous public health problem, both in the world and in our country. However, despite a comprehensive program of prevention and control, there is still very little progress in this field, especially when it comes to middle-income and developing countries.
\end{abstract}

\section{What this Study Adds}

In our study we emphasized the importance of the defined problem, pointed out the necessity of educational programs especially for adolescents as a significant STI population group.

Authors' Contributions: Conceptions and design VS and AM; Acquisition, analysis and interpretation of data: VS, AM, SS and JA; Drafting the article: SS and JA; Revising it critically for important intellectual content: VS and JA; Approved final version of the manuscript: VA, AM, SS and JA.

Conflict of Interest: The authors declare that they have no conflict of interest.

\section{References}

1. World Health Organization. Report on global sexually transmitted infections surveillance 2018 . Geneva: World Health Organization; 2018. [cited 2019 Apr 1]. Avaliable from: https://apps.who.int/iris/ 
bitstream/handle/10665/277258/9789241565691eng.pdf.

2. Li C, Cheng Z, Wu T, Liang X, Gaoshan J, Li L, et al. The relationships of school-based sexuality education, sexual knowledge and sexual behaviors-a study of 18,000 Chinese college students. Reprod Health. 2017;14(1):103.

3. Mokdad AH, Forouzanfar MH, Daoud F, Mokdad AA, El Bcheraoui C, Moradi-Lakeh M,et al. Global burden of diseases, injuries, and risk factors for young people's health during 1990-2013: a systematic analysis for the Global Burden of Disease Study 2013. Lancet. 2016;387(10036):2383-401.

4. Borges ALV, Chofakian CBN, Sato APS, Fujimori E, Duarte LS, Gomes MN. Fertility rates among very young adolescent women: temporal and spatial trends in Brazil. BMC Pregnancy Childbirth. 2016;16:57.

5. World Health Organization. Sexually transmitted infections (STIs). [cited 2018 Jan 18]. Availablefrom: http://www.who.int/mediacentre/factsheets/fs110/en/.

6. Mahmutovic Vranic S, Ademovic E, Seremet M, Jusic A, Vukas E. Sexual behaviours toward sexually transmitted infections: A cross-sectional survey among undergraduate medical students. HealthMed. 2013:7(7):2208.

7. Selak S, Jurić V, Hren D, Jurić M. What do young people from Mostar, Bosnia and Herzegovina know about contraception and sexual health? Croat Med J. 2004;45(1):44-9.

8. Uusküla A, Puur A, Toompere K, DeHovitz J. Trends in the epidemiology of bacterial sexually transmitted infections in eastern Europe, 19952005. Sex Transm Infect. 2010;86(1):6-14.

9. Noll, JG, Trickett PK, Putnam FW. A prospective investigation of the impact of childhood sexual abuse on the development of sexuality. J Consult Clin Psychol. 2003;71(3):575-86.

10. Jomeen J, Whitfield CA. East Riding Teenage Pregnancy \& Young Peoples Advisory Board: A Survey of Teenage Sexual Health: Knowledge, Behaviour and Attitudes in East Yorkshire. Kingston upon Hull, UK: University of Hull; 2010.
11. Coulter A. Sexual sensation seeking and self-efficacy's relationship to sexual risk taking behaviour [dissertation]. Arcata, CA: The Faculty of Humboldt State University; 2007.

12. Eaton DK, Kann L, Kinchen S, Shanklin S, Flint $\mathrm{KH}$, Hawkins J, et al. Youth risk behavior surveillance - United States, 2011. MMWR Surveill Summ. 2012;61(4):1-162.

13. Drago F, Ciccarese G, Zangrillo F, Gasparini G, Cogorno L, Riva S, et al. A Survey of Current Knowledge on Sexually Transmitted Diseases and Sexual Behaviour in Italian Adolescents. Int J Environ Res Public Health. 2016;13(4):422.

14. von Rosen FT, von Rosen AJ, Müller-Riemenschneider F, Damberg I, Tinnemann P. STI Knowledge in Berlin Adolescents. Int J Environ Res Public Health. 2018;15(1):110.

15. Thapa KB, Chand SB. Knowledge and awareness about sexually transmitted infections among higher secondary school students in Bajhang, Nepal. MOJ Public Health. 2018:7(3):101-6.

16. Hossain M, Mani KK, Sidik SM, Shahar HK, Islam R. Knowledge and awareness about STDs among Women in Bangladesh. BMC Public Health. 2014;14:775.

17. Amu EO, Adegum PT. Awareness and Knowledge of Sexually Transmitted Infections among Secondary School Adolescents in Ado Ekiti, South Western Nigeria. Journal of Sexually Transmitted Diseases. 2015;260126:7 pages.

18. Hirsl-Hecej V, Stulhofer A. Condom use and its consistency among metropolitan high school students in Croatia, 1997-2001: has anything changed? Coll Antropol. 2006; 30(Suppl. 2):71-8.

19. Manlove J, Ryan S, Franzetta K. Contraceptive use and consistency in U.S. teenagers $₫$ most recent sexual relationship. Perspect Sex Reproduct Health. 2004:36(6):265-75.

20. Croatian Institute of Public Health [in Croatian] [cited 2019 Feb 20]. Available from: http://hzjz.hr/ wp-content/uploads/2014/04/ljetopis_2013_.pdf.

21. Rosenberg MD, Gurvey JE, Adler N, Dunlop MB, Ellen JM. Concurrent sex partners and risk for sexually transmitted diseases among adolescents. Sex Transm Dis. 1999;26(4):208-12. 